\title{
Laplace transform solution of conjugate heat and mass transfer in falling film absorption process
}

\author{
Mehdi Mortazavi and Saeed Moghaddam* \\ Department of Mechanical and Aerospace Engineering, University of Florida \\ Gainesville, FL 32603, USA \\ E-mail: saeedmog@ufl.edu
}

Keywords: Absorption cooling/heating system, Falling film absorber, Lithium bromide, Laplace transform solutions

\begin{abstract}
In this study, the conjugate heat and mass transfer process taking place during the absorption of a refrigerant vapor into a falling liquid film is analyzed using the Laplace transform method. The Laplace transform method has been previously utilized to model the process but under a uniform velocity profile assumption. Here, a more realistic linear velocity profile is employed. The results suggest that the uniform velocity profile assumption overestimates the refrigerant concentration across the liquid film, and underestimates the temperature profile and the vapor absorption rate. Overall, the uniform velocity profile assumption can result in up to $30 \%$ error in calculating the absorption rate. Using the new model, the effect of different flow parameters on the absorption rate has been studied. The efficacy of the model is demonstrated through comparison with various experimental and numerical results reported in the literature. The analytical solution developed in the present study provides a simple, fast and accurate approach for calculating the absorption rate at different operating conditions and fluid properties.
\end{abstract}

\begin{tabular}{|lrll|}
\hline \multicolumn{2}{l}{ Nomenclature } & & \\
$A_{i}$ & \multicolumn{1}{l}{ Airy function } & Greek letters & \\
$B=\left(\mathrm{T}_{e}-\mathrm{T}_{0}\right) /\left(C_{e}-C_{0}\right) \quad$ Slope of saturation curve & $\alpha=\lambda /\left(\rho \cdot c_{p}\right) \quad$ Thermal diffusivity $\left(\mathrm{m}^{2} \mathrm{~s}^{-1}\right)$ \\
$B_{i}$ & Airy function & $\eta$ & Non-dimensional y-coordinate \\
\hline
\end{tabular}




\begin{tabular}{|c|c|c|c|}
\hline$C$ & Refrigerant concentration $\left(\mathrm{kg} \mathrm{kg}^{-1}\right)$ & $\xi$ & Non-dimensional x-coordinate \\
\hline$c_{P}$ & Heat capacity $\left(\mathrm{J} \mathrm{kg}^{-1} \mathrm{~K}^{-1}\right)$ & $\theta$ & Non-dimensional temperature \\
\hline$C_{1}, \ldots, C_{4}$ & Constants & $\gamma$ & Non-dimensional concentration \\
\hline$D$ & Diffusion coefficient $\left(\mathrm{m}^{2} \mathrm{~s}^{-1}\right)$ & $\delta$ & Solution film thickness (m) \\
\hline$\Delta h_{a b s}$ & Heat of absorption $\left(\mathrm{J} \mathrm{kg}^{-1}\right)$ & $\lambda$ & Thermal conductivity $\left(\mathrm{W} \mathrm{m}^{-1} \mathrm{~K}^{-1}\right)$ \\
\hline$k_{1}, k_{2}$ & Constants (K) & $\rho$ & Density $\left(\mathrm{kg} \mathrm{m}^{-3}\right)$ \\
\hline$L e=\alpha / D$ & Lewis number & $\Gamma$ & Flow rate $\left(\mathrm{kg} \mathrm{min} \mathrm{mi}^{-1}\right)$ \\
\hline$s$ & Laplace transform variable & & \\
\hline$S t=\left(c_{P} \cdot \mathrm{B}\right) /$ & $\left(\Delta \mathrm{h}_{a b s}\right) \quad$ Modified Stefan number & Subscripts & \\
\hline$T$ & Temperature $(\mathrm{K})$ & 0 & Inlet condition \\
\hline$u$ & Longitudinal velocity $\left(\mathrm{m} \mathrm{s}^{-1}\right)$ & $e$ & Equilibrium \\
\hline $\bar{u}$ & Average velocity $\left(\mathrm{m} \mathrm{s}^{-1}\right)$ & $i$ & Liquid-vapor interface \\
\hline$x$ & Longitudinal coordinate (m) & $s$ & Absorbent ( $\mathrm{LiBr}$ solution) \\
\hline$y$ & Transversal coordinate $(\mathrm{m})$ & $w$ & Cooling wall \\
\hline
\end{tabular}

\section{Introduction}

Absorption refrigeration systems (ARSs) are fundamentally attractive for our future energy economy because they can harness low quality heat energy for cooling. Their use is particularly attractive in combined heating, cooling, and power (CCHP) systems in which the ARS is powered by waste heat (Kim and Infante Ferreira, 2008; Saha et al., 2001). In the past several years, this field has seen an upsurge in research activities with the introduction of new heat exchanger configurations (Bigham et al., 2014a, 2014b; Cerezo et al., 2009; Nasr Isfahani et al., 2014, 2013; Palacios et al., 2009; Warnakulasuriya and Worek, 2008) and ionic liquid (IL) absorbents (Dong et al., 2012; Kurnia et al., 2014; Zheng et al., 2014) that promise compact and robust systems. A better understanding of the transport processes involved in an absorption system is key to their development efforts. One of the fundamental processes taking place in an ARS is the absorption process that involves transport of refrigerant molecules into the absorbent solution in an exothermic process. The heat generated must be removed from the absorbent to perpetuate the absorption process. Understanding the transport phenomenon involved in the absorption process is essential in design of absorbers and performance 
evaluation of new refrigerant-absorbent pairs (Jeong and Garimella, 2002; Nasr Isfahani et al., 2013; Zheng et al., 2014).

The conjugate heat and mass transfer problem associated with the absorption process has been studied both analytically and numerically. Numerical simulations provide more accurate results, and are applicable to more complex geometries. Analytical solutions, on the other hand, are more efficient in terms of the computational efforts, and easier for design purposes. Nakoryakov and Grigoreva (Grigoryeva and Nakoryakov, 1977; Nakoryakov and Grigor'eva, 1977; Nakoryakov et al., 1997) presented the first analytical solution using the Fourier transform method and a set of simplifying assumptions. In their model, the interface is assumed to reach thermodynamic equilibrium instantly, as the flow enters the solution domain. Also, a linear relationship between the refrigerant concentration and temperature at different vapor pressures is assumed. Furthermore, the authors considered a uniform velocity profile instead of the actual parabolic velocity profile with the solution film and derived an analytical solution for an isothermal wall over which the absorbent flows. Grossman (Grossman, 1983) improved the Nakoryakov and Grigoreva's (Grigoryeva and Nakoryakov, 1977) model by using a parabolic velocity profile. However, solutions based on the Fourier method do not accommodate for inlet film conditions that differ from the solution domain boundary conditions (Nakoryakov and Grigoryeva, 2010). At the entrance region, oscillations occur in the solution due to disagreements between the inlet and the interface boundary conditions. Consequently, the Fourier solution is not applicable for the entire flow domain, and the entrance region needs to be treated separately. Nakoryakov et al. (Nakoryakov et al., 2011) used a selfsimilar solution at the entrance region to avoid such difficulty, and Grossman (Grossman, 1983) used a numerical approach for the entrance region.

Recently, Meyer (Meyer, 2014) has introduced the Laplace transform method to solve the coupled partial differential equations for heat and mass transfer in laminar falling films. The flow velocity profile is assumed to be uniform. Adiabatic as well as isothermal walls are considered and compared. Unlike the Fourier method, the Laplace transform method is applicable over the entire flow length.

In the present study, the Laplace transform method is similarly applied to a laminar falling film flow but with a more realistic linear velocity profile. The model is then used 
to study the effect of operating conditions such as vapor pressure and solution flow rate on the absorption rate, and the results are compared with the available data in the literature.

\section{Model}

Fig. 1 depicts the flow domain composed of the absorbent (lithium bromide, LiBr) and refrigerant (water) solution flowing down a vertical wall. The solution film is in contact with an isothermal wall (left) and the water vapor (right) at a constant pressure $P$. The solution enters the domain at $x=0$ with a uniform refrigerant concentration $\left(C_{0}\right)$ and temperature $\left(T_{0}\right)$ at an equilibrium water vapor pressure of $P_{0}$. The $\mathrm{LiBr}$ remains in the liquid phase while the water vapor may be absorbed into the $\mathrm{LiBr}$ solution. Absorption of the water vapor into the solution film takes place at the solution-vapor interface as a result of the pressure potential between the liquid and vapor phases $\left(P-P_{0}\right)$. The heat generated at the solution-vapor interface transfers into the isothermal wall. This model can be extended to a falling film over a horizontal tube, if the film thickness is significantly smaller than the tube diameter (Karami and Farhanieh, 2009).

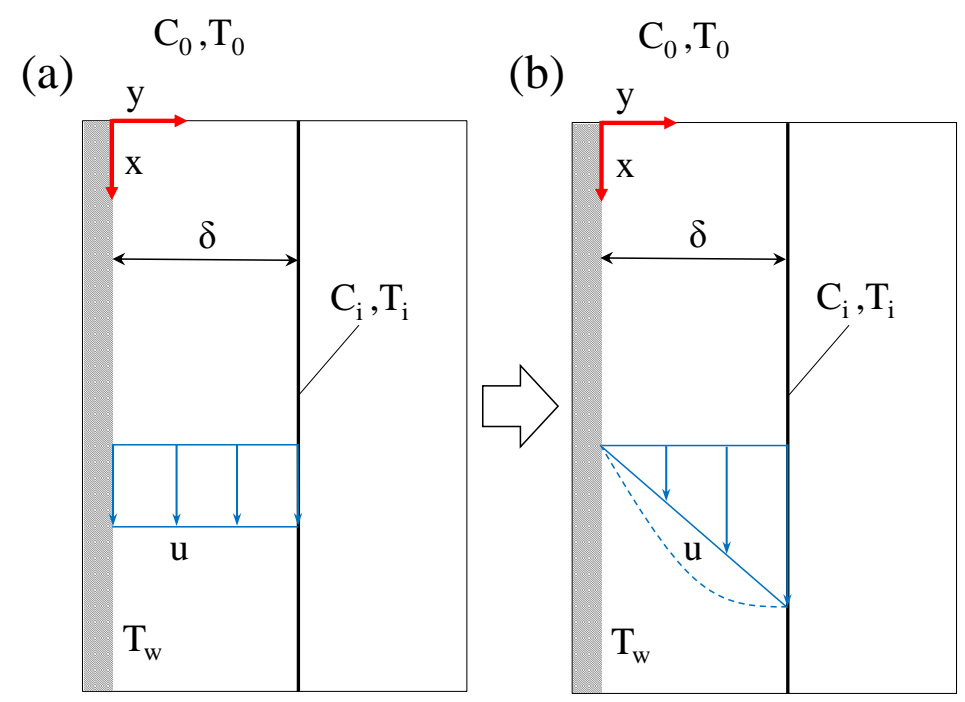

Figure 1. A schematic of the flow domain depicting the difference between the uniform velocity (a) and linear velocity (b) profile assumptions. The dashed curve on (b) depicts the actual velocity profile. 


\subsection{Governing equations}

The governing differential equations are the energy and species balance equations in the Cartesian coordinates (Meyer, 2014).

$$
\begin{gathered}
u \frac{\partial C}{\partial x}=D_{s} \frac{\partial^{2} C}{\partial y^{2}} \\
u \frac{\partial T}{\partial x}=\alpha_{s} \frac{\partial^{2} T}{\partial y^{2}}
\end{gathered}
$$

where $u$ is the velocity in the flow direction, $D_{s}$ is the diffusion coefficient, $\alpha_{s}$ is the thermal diffusivity, $C$ is the refrigerant concentration and $T$ is the temperature. Note that the diffusive terms in the flow direction are neglected. The following simplifying assumptions also are made for solving the governing equations:

a) The thermophysical properties such as thermal conductivity, viscosity, heat of absorption and diffusion coefficient are assumed constant.

b) The parabolic velocity profile obtained by solving the momentum equation is replaced by a linear velocity profile (Fig. 1).

$u=2 \bar{u} \underline{y}=2 \bar{u}$

c) The film thickness slightly increases along the flow direction due to the absorption of the water vapor. However, the absorbed water vapor is small and the solution flow and the film thickness are assumed to remain constant (Fig.1).

d) The $\mathrm{LiBr}$ solution is considered to be non-volatile; hence the mass transfer resistance in the gas phase is neglected (Grossman, 1983; Nakoryakov and Grigoryeva, 2010; Nakoryakov et al., 2011).

\subsection{Boundary conditions}

A total of 6 boundary conditions ( 2 in the $x$ direction and 4 in the $y$ direction) are needed to solve the set of governing equations. At the entrance $(x=0)$, the solution enters the absorber at a uniform concentration and temperature.

$C(0, y)=C_{0}$

$T(0, y)=T_{0}$

The wall is impermeable, and assumed to be at a constant temperature. 
$\frac{\partial C(x, 0)}{\partial y}=0$

$T(x, 0)=T_{w}$

At the interface, we assume thermodynamic equilibrium. At each vapor pressure, a linear relationship is assumed between the temperature and the refrigerant concentration, as shown in Fig. 2 (Grossman, 1983; Meyer, 2014; Nakoryakov and Grigoryeva, 2010; Nakoryakov et al., 2011).

$T(x, \delta)=k_{1}-k_{2} C(x, \delta)(8)$

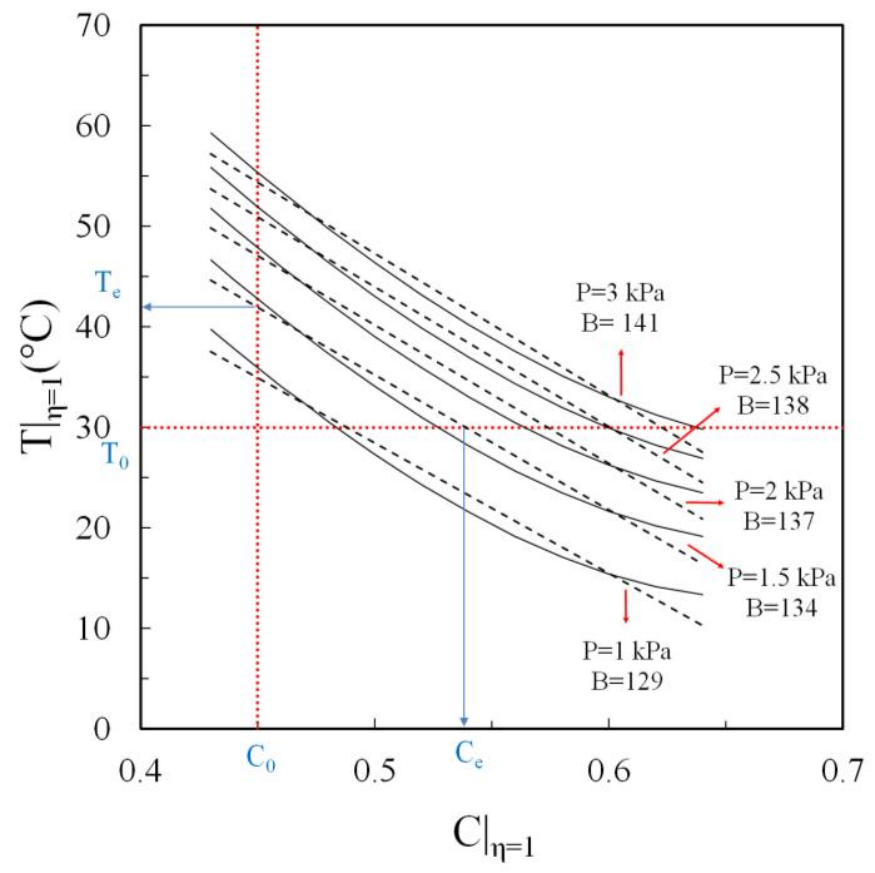

Figure 2. Saturation curve at the interface as a function of vapor pressure. Note that $B=k_{2}$ is the slope of the straight dashed line that best fits the saturation curve at a specific pressure.

The solution conducts the absorbed heat from the interface to the cooling surface. The energy balance at the interface can then be written as

$\rho_{s} D_{s} \frac{\partial C(x, \delta)}{\partial y} \Delta h_{a b s}=\lambda_{s} \frac{\partial T(x, \delta)}{\partial y}$ 


\subsection{Non-dimensionalization of the governing equation and boundary conditions}

The concentration and temperature are non-dimensionalized by using the concentration and temperature at the entrance as well as their corresponding equilibrium temperature and concentration. Note that $C_{e}$ is the equilibrium refrigerant concentration corresponding to $T_{0}$ and $T_{e}$ is the equilibrium temperature corresponding to $C_{0}$, as shown in Fig. A.1 in Appendix A.

$$
\begin{gathered}
\gamma=\frac{C-C_{0}}{C_{e}-C_{0}} \\
\theta=\frac{T-T_{0}}{T_{e}-T_{0}}
\end{gathered}
$$

The $x$ and $y$ coordinates are normalized by using the film thickness and the average solution velocity

$$
\begin{aligned}
\eta & =\frac{y}{\delta} \\
\xi & =\frac{x}{\delta} \frac{\alpha}{2 \bar{u} \delta}
\end{aligned}
$$

By substituting Eqs.10-13 along with the linear velocity profile (Eq.3) into the governing differential equations, the non-dimensional differential equations are obtained

$$
\eta \frac{\partial \gamma}{\partial \xi}=\frac{1}{L e} \frac{\partial^{2} \gamma}{\partial \eta^{2}}
$$

$$
\eta \frac{\partial \theta}{\partial \xi}=\frac{\partial^{2} \theta}{\partial \eta^{2}}
$$

where

$$
L e=\frac{\alpha}{D}
$$

The Lewis number $(L e)$ is defined as the ratio of the thermal to mass diffusivities. The non-dimensional boundary conditions can be written as

$$
\begin{aligned}
& \gamma(0, \eta)=0 \\
& \theta(0, \eta)=0 \\
& \frac{\partial \gamma(\xi, \eta=0)}{\partial \eta}=0
\end{aligned}
$$


$\theta(\xi, \eta=0)=\theta_{w} \quad(20)$

$\theta(\xi, \eta=1)+\gamma(\xi, \eta=1)=1($ see Appendix A) $(21)$

$\frac{\partial \gamma(\xi, \eta=1)}{\partial \eta}=L e \cdot S t \frac{\partial \theta(\xi, \eta=1)}{\partial \eta}$

where

$S t=\frac{c_{P}\left(T_{e}-T_{0}\right)}{\Delta h_{a b s}\left(C_{e}-C_{0}\right)}=\frac{c_{P} \cdot B}{\Delta h_{a b s}}$

is the modified Stefan number defined as the sensible to latent heat ratio.

2.4 Laplace transforms

Taking the Laplace transform of the governing equations with respect to the nondimensional longitudinal direction $(\xi)$ gives

$\eta[s \cdot \gamma(s, \eta)-\gamma(\xi=0, \eta)]=\frac{1}{L e} \frac{\partial^{2} \gamma(s, \eta)}{\partial \eta^{2}}$

$\eta[s \cdot \theta(s, \eta)-\theta(\xi=0, \eta)]=\frac{\partial^{2} \theta(s, \eta)}{\partial \eta^{2}}$

Using the initial conditions, the final differential equations in the Laplace domain are obtained

$\frac{\partial^{2} \gamma(s, \eta)}{\partial \eta^{2}}=L e \cdot s \cdot \eta \cdot \gamma(s, \eta)$

$\frac{\partial^{2} \theta(s, \eta)}{\partial \eta^{2}}=s \cdot \eta \cdot \theta(s, \eta)$

Solution to the above differential equations is provided below

$$
\begin{aligned}
& \gamma(s, \eta)=C_{1} A_{i}(\sqrt[3]{L e \cdot s} \eta)+C_{2} B_{i}(\sqrt[3]{L e \cdot s} \eta) \\
& \theta(s, \eta)=C_{3} A_{i}(\sqrt[3]{s} \eta)+C_{4} B_{i}(\sqrt[3]{s} \eta)
\end{aligned}
$$


where $A_{i}$ and $B_{i}$ are Airy functions. Note that $b=A_{i}(a)$ and $b=B_{i}(a)$ are two linearly independent solutions of Airy equation or Stokes equation $\left(b^{\prime \prime}-a b=0\right)$. Two boundary conditions for the solution concentration and temperature at the entrance have already been utilized to transform the governing equations to the Laplace domain. The remaining 4 boundary conditions need to be transformed to the Laplace domain. The boundary conditions at the isothermal wall and the interface are transformed as

$$
\begin{aligned}
& \frac{\partial \gamma(s, \eta=0)}{\partial \eta}=0 \\
& \theta(s, \eta=0)=\frac{\theta_{w}}{s} \\
& \theta(s, \eta=1)+\gamma(s, \eta=1)=\frac{1}{s} \\
& \frac{\partial(s, \eta=1)}{\partial \eta}=L e \cdot S t \frac{\partial \theta(s, \eta=1)}{\partial \eta}
\end{aligned}
$$

By substituting the boundary conditions (i.e. Eqs. 30-33) into the concentration and temperature equations in the Laplace domain (i.e. Eqs. 28 and 29), constants $C_{1} \ldots C_{4}$ are determined.

$$
\begin{aligned}
& C_{1}=\frac{-B_{i}^{\prime}(0) \cdot f_{1}(s)}{f_{2}(s)} \\
& C_{2}=\frac{f_{1}(s)}{f_{2}(s)} \\
& C_{3}=\frac{1}{s \cdot A_{i}(0)}\left(\theta_{w}-\frac{f_{3}(s) \cdot B_{i}(0)}{f_{4}(s)}\right) \\
& C_{4}=\frac{f_{3}(s)}{f_{2}(s)}
\end{aligned}
$$

where

$$
f_{1}(s)=A_{i}^{\prime}(0) \cdot L e^{2 / 3} \cdot S t \cdot\left[B_{i}^{\prime}(\sqrt[3]{s})\left(A_{i}(0)-\theta_{w} \cdot A_{i}(\sqrt[3]{s})\right)-A_{i}^{\prime}(\sqrt[3]{s})\left(B_{i}(0)-\theta_{w} \cdot B_{i}(\sqrt[3]{s})\right)\right]
$$




$$
\begin{aligned}
& f_{2}(s)=s \cdot\left(A_{i}(0) B_{i}(\sqrt[3]{s})-B_{i}(0) A_{i}(\sqrt[3]{s})\right) \cdot\left(A_{i}^{\prime}(0) B_{i}^{\prime}(\sqrt[3]{L e \cdot s})-B_{i}(0) A_{i}(\sqrt[3]{L e \cdot s})\right)+ \\
& s \cdot L e^{2 / 3} \cdot S t \cdot\left(A_{i}(0) B_{i}^{\prime}(\sqrt[3]{s})-B_{i}(0) A_{i}^{\prime}(\sqrt[3]{s})\right) \cdot\left(A_{i}^{\prime}(0) B_{i}(\sqrt[3]{L e \cdot s})-B_{i}^{\prime}(0) A_{i}(\sqrt[3]{L e \cdot s})\right) \\
& f_{3}(s)=\left(A_{i}^{\prime}(0) B_{i}^{\prime}(\sqrt[3]{L e \cdot s})-B_{i}^{\prime}(0) A_{i}^{\prime}(\sqrt[3]{L e \cdot s})\right) \cdot\left(A_{i}(0)-\theta_{w} \cdot A_{i}(\sqrt[3]{s})\right) \\
& -L e^{2 / 3} \cdot S t \cdot \theta_{w} \cdot A_{i}^{\prime}(\sqrt[3]{s}) \cdot\left(A_{i}^{\prime}(0) B_{i}(\sqrt[3]{L e \cdot s})-B_{i}^{\prime}(0) A_{i}(\sqrt[3]{L e \cdot s})\right) \\
& f_{4}(s)=\frac{f_{2}(s)}{s} \quad(41)
\end{aligned}
$$

By substituting $C_{1} \ldots C_{4}$ into Eqs. 28 and 29, the concentration and temperature equations in the Laplace domain are obtained

$$
\begin{aligned}
& \gamma(s, \eta)=\frac{f_{1}(s)}{A_{i}^{\prime}(0) \cdot f_{2}(s)}\left[A_{i}^{\prime}(0) \cdot B_{i}(\sqrt[3]{L e . s} \eta)-B_{i}^{\prime}(0) \cdot A_{i}(\sqrt[3]{L e \cdot s} \eta)\right] \\
& \theta(s, \eta)=\frac{1}{A_{i}(0) \cdot f_{2}(s)}\left[\left(\theta_{w} \cdot f_{4}(s)-f_{4}(s)\right) \cdot A_{i}(\sqrt[3]{s} \eta)+f_{3}(s) \cdot A_{i}(0) \cdot B_{i}(\sqrt[3]{s} \eta)\right]
\end{aligned}
$$

\subsection{Inverse Laplace transforms}

The Residue theorem can be utilized to determine the inverse Laplace transform when the transform is complicated and does not appear in tables (Scott et al., 1985). As shown in Appendix B, the inverse Laplace of a complex function $F(s)$ can be obtained by calculating sum of the residues of $F(s) \mathrm{e}^{s t}$ at singularities of $F(s)$

$$
f(t)=\sum_{n=1}^{N} \operatorname{Re}_{s=s_{n}}\left[e^{s t} F(s)\right]
$$

Depending on the singularity type (simple poles, simple complex roots and repeated roots) different methods are utilized to calculate the residues (Scott et al., 1985). A function $F(s)$ in the form of $F(s)=p(s) / q(s)$ has a simple pole at $s_{0}$, if $p\left(s_{0}\right) \neq 0$ and $q$ has a zero of order 1 at $s_{0}$, and $q^{\prime}\left(\mathrm{s}_{0}\right) \neq 0$. For this case, the residue of $F(s)$ at point $s_{0}$ is

$$
\operatorname{Re}_{s=s_{0}} s(F(s))=\operatorname{Re}_{s=s_{0}} s \frac{p(s)}{q(s)}=\frac{p\left(s_{0}\right)}{q^{\prime}\left(s_{0}\right)}
$$


In order to find the inverse Laplace of the concentration and temperature equations (Eqs. 42 and 43), the poles of the equations need to be found by finding the zeros of the denominators of their corresponding equations. Note that the denominators of Eqs. 42 and 43 have similar zeros (zeros of $f_{2}(s)$ ). The roots of function $f_{2}(s)$ for $L e=100$ and $S t=0.1$ (the choice and range of $L e$ and $S t$ will be discussed later) are calculated numerically and are shown in Fig. 3. Note that all the poles are simple poles because

$p_{\gamma}\left(s_{n}\right) \neq 0, \mathrm{p}_{\theta}\left(s_{n}\right) \neq 0, q_{\gamma}^{\prime}\left(s_{n}\right) \neq 0, q_{\theta}^{\prime}\left(s_{n}\right) \neq 0(n=1,2, \ldots)$

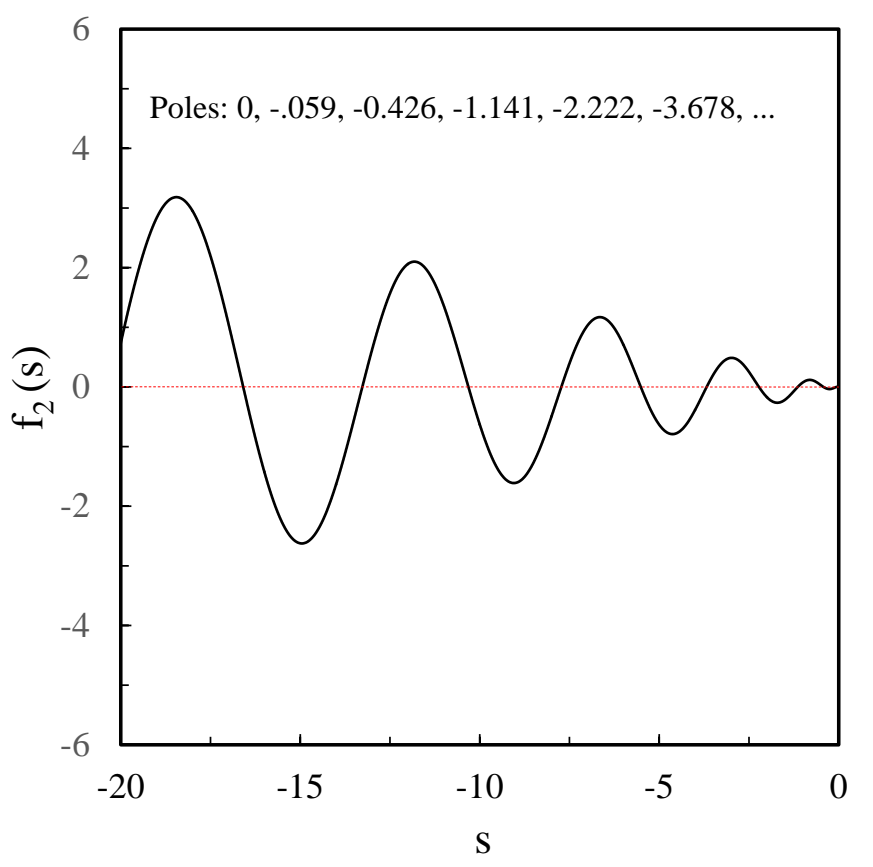

Figure 3. Poles of the concentration and temperature equations for $L e=100$ and $S t=0.1$

where the concentration and temperature profiles in the Laplace domain are written in the forms of

$\gamma(s, \eta)=\frac{p_{\gamma}(s)}{q_{\gamma}(s)}(47)$ 


$$
\theta(s, \eta)=\frac{p_{\theta}(s)}{q_{\theta}(s)}
$$

Note that $p_{\gamma}(s)$ and $p_{\theta}(s)$ are numerators and $q_{\gamma}(s)$ and $q_{\theta}(s)$ are denominators of Eq. 42 and Eq. 43, respectively.

Hence, Eq. 44 and Eq. 45 can be used to find the inverse Laplace as follow

$$
\begin{aligned}
& \gamma(\xi, \eta)=\sum_{n=1}^{N} \frac{e^{s_{n} \cdot \xi} p_{\gamma}\left(s_{n}\right)}{q_{\gamma}^{\prime}\left(s_{n}\right)} \quad(\mathrm{n}=1,2, \ldots) \\
& \theta(\xi, \eta)=\sum_{n=1}^{N} \frac{e^{s_{n} \cdot \xi} p_{\theta}\left(s_{n}\right)}{q_{\theta}^{\prime}\left(s_{n}\right)} \quad(\mathrm{n}=1,2, \ldots)
\end{aligned}
$$

\section{Results and discussion}

In this section, we first compare the results of our model with the Meyer's model (Meyer, 2014) developed under a uniform velocity profile assumption. In the second part of this section, we use our model to study the effect of different working conditions on the absorption rate.

\subsection{Comparison of results with uniform and linear velocity assumptions}

\subsubsection{Concentration and temperature profiles}

The concentration and temperature profiles across the solution film as well as the dimensionless local mass flux at the interface for $L e=100$ and $S t=0.1$ are compared in Figs. 4-6 for the uniform (dashed lines) and linear (solid lines) velocity profiles. A $L e=100$ is used here to compare the results of our model with those of Meyer (Meyer, 2014). However, the $L e$ values provided for the $\mathrm{LiBr}$ solution in the literature vary widely, between 50 to 500 , due to a range of values (between $210^{10}$ to $210^{9}$ ) suggested for $D_{s}$. However, in the next section, to study the effect of absorber working conditions on the absorption rate we use $L e=257$ corresponding to a mass diffusion coefficient of $D_{s}=5 \times 10^{-10}$. This value of diffusion coefficient is verified through our extensive experimental and numerical studies (Bigham et al., 2014b; Mortazavi et al., 
2015; Nasr Isfahani and Moghaddam, 2013; Yu et al., 2012), and recently through direct measurements using pulsed field gradient nuclear magnetic resonance (PFG-NMR) technique. The $S t$ number varies from 0.1 to 0.11 as the vapor pressure changes from $1000 \mathrm{~Pa}$ to $3000 \mathrm{~Pa}$. A $S t=0.1$ is used here to compare the results of our model with those of Meyer (Meyer, 2014).

The non-dimensional refrigerant concentration $(\gamma)$ across the solution film thickness $(\eta)$ at different flow length $(\xi)$ for uniform (dashed lines) and linear (solid lines) velocity profiles is provided in Fig. 4a. The cooling wall is kept at a constant temperature of $\theta_{w}=-1$. For a film entering the domain at $T_{0}=30^{\circ} \mathrm{C}$, and at a vapor pressure of $\mathrm{P}=1000 \mathrm{~Pa}, \theta_{w}=-1$ is equivalent to a wall temperature of $T_{w} \approx 25^{\circ} \mathrm{C}$, which is a typical operating condition in a $\mathrm{LiBr}$ absorption system (Islam, 2008; Nasr Isfahani and Moghaddam, 2013). Since the solution enters the absorber at a subcooled state, the refrigerant concentration at the interface $(\gamma(\xi, \eta=1))$ increases as soon as it comes into contact with the vapor. A thin concentration boundary layer forms at the entrance region and rapidly grows until it reaches the cooling wall at $\xi \approx 3$. A flow length of $\xi=3$ corresponds to a falling distance of approximately $15 \mathrm{~mm}$ at a solution film velocity and thickness of $\bar{u}=0.03 \mathrm{~m} \mathrm{~s}^{-1}$ and $\delta=180 \mu \mathrm{m}$, respectively. Note that the falling film absorption systems typically work at a flow rate range of $0.3-10 \mathrm{~kg} \mathrm{~min}^{-1} \mathrm{~m}^{-1}$. According to Eq. 51 and 52 , this flow rate range results in a film thickness range of $150-500 \mu \mathrm{m}$ and a film velocity range of 0.02-0.2 $\mathrm{m} \mathrm{s}^{-1}$ (Mortazavi et al., 2015).

$$
\begin{aligned}
& \delta=\left(\frac{3 \mu_{s} \Gamma}{\rho_{s}^{2} g}\right)^{\frac{1}{3}} \\
& \bar{u}=\frac{\Gamma}{\rho_{s} \delta}
\end{aligned}
$$

At the entrance region $(\xi \leq 0.01)$, the two concentration profiles for the uniform and linear velocity profiles show a negligible difference. The difference between the two becomes more pronounced at higher flow lengths. It can be clearly seen that the uniform velocity profile overestimates the refrigerant concentration profile across the solution film. 
The temperature profiles across the solution film are provided in Fig. $\mathbf{4 b}$. The cooling wall temperature is kept at $\theta_{w}=-1$. At the entrance region, the interface temperature rises above the inlet temperature $\left(\theta_{0}=0\right)$ due to the heat of absorption. The concurrent heating and cooling of the solution at its interfaces with the vapor phase and the cooling wall, respectively, result in growth of two thermal boundary layers on two sides of the solution flow. The two boundary layers meet at a flow length of approximately $\xi \approx 0.01$. A flow length of $\xi=0.01$ corresponds to a falling distance of approximately $50 \mu \mathrm{m}$ at a solution film velocity and thickness of $\bar{u}=0.03 \mathrm{~m} \mathrm{~s}^{-1}$ and $\delta=180 \mu \mathrm{m}$, respectively. Fig. $4 \mathrm{~b}$ shows that the uniform velocity assumption underestimates the temperature profile at different flow lengths. 


\section{(a)}

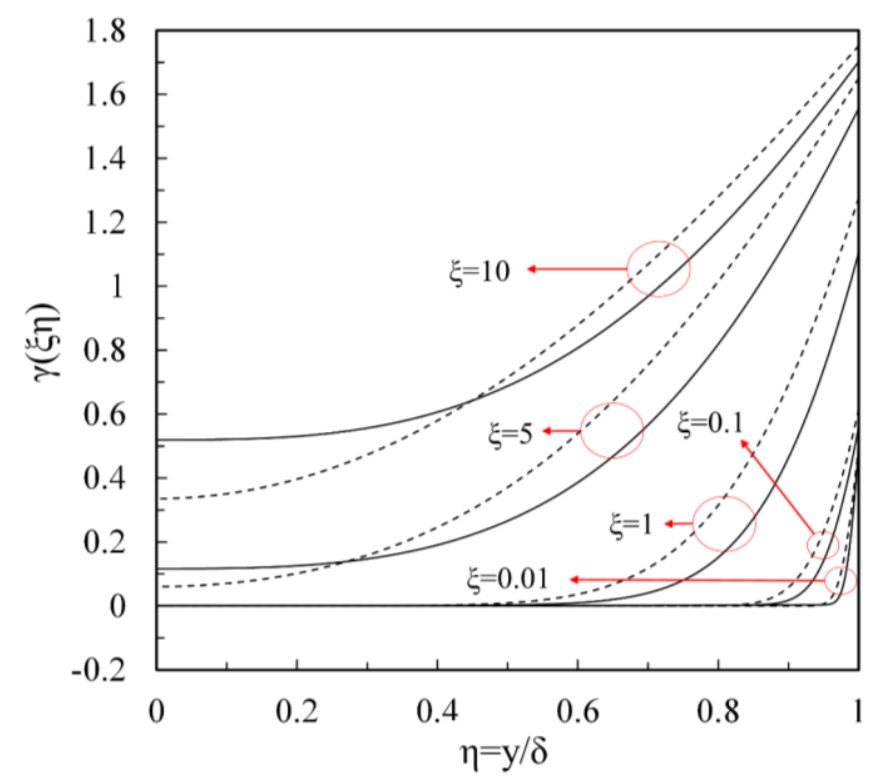

(b)

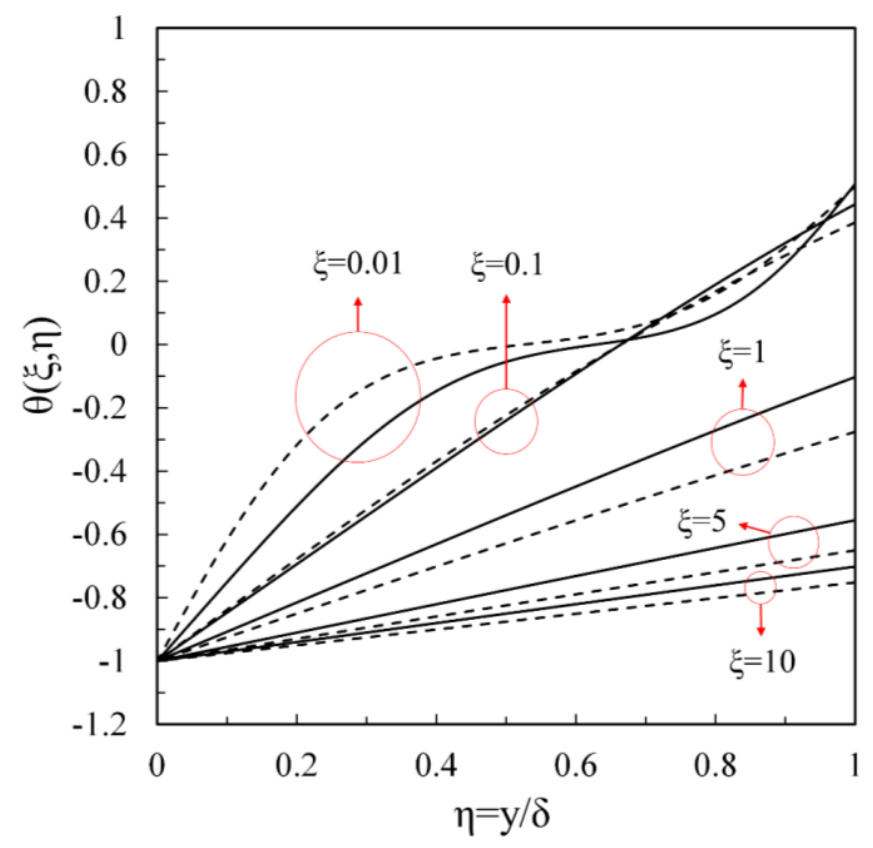

Figure 4. Dimensionless concentration (a) and temperature (b) profiles across the film for different values of $\xi$ for the uniform velocity (dashed lines) and linear velocity (solid line) profiles; $L e=100, S t=0.1$ and $\theta_{w}=-1$ 
(a)

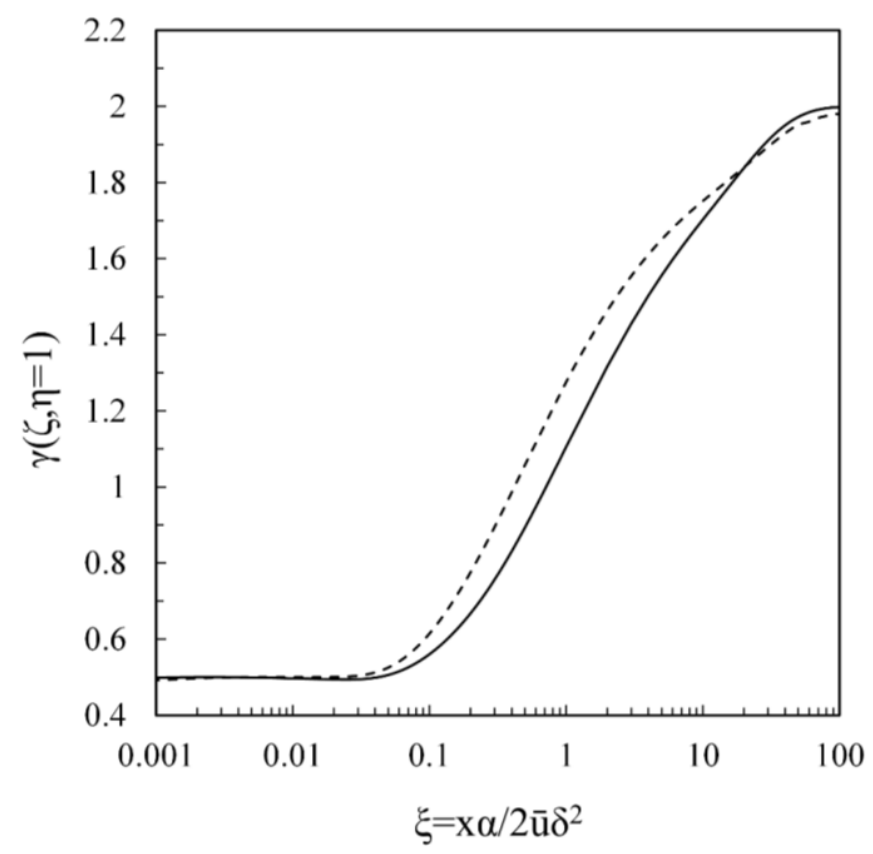

(b)

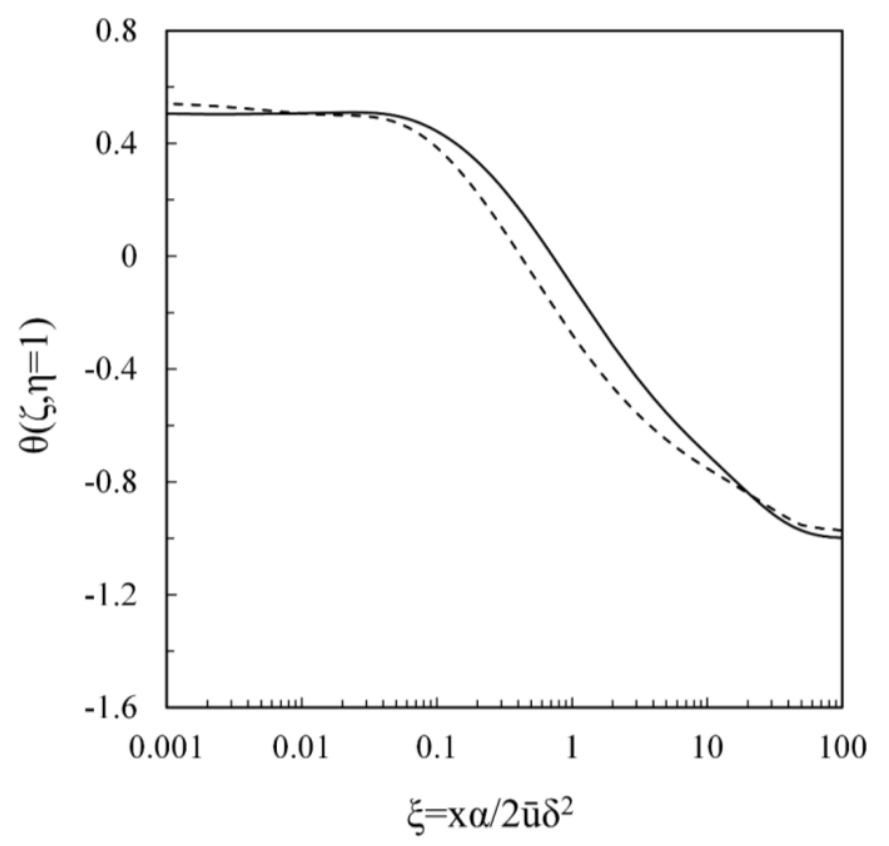

Figure 5. Dimensionless concentration (a) and temperature (b) at the interface for different values of $\xi$ for the uniform velocity (dashed lines) and linear velocity (solid line) profiles; $L e=100, S t=0.1$ and $\theta_{w}=-1$

The non-dimensional concentration and temperature at the interface (i.e, $\gamma(\xi, \eta=1)$ and $\theta(\xi, \eta=1))$ are presented in Fig. 5. The difference between the two curves is 
insignificant up to $\xi=0.05$. The uniform velocity profile overestimates and underestimates the refrigerant concentration and temperature profiles, respectively.

\subsubsection{Local mass flux}

The local non-dimensional mass flux at the interface at each flow length $(\xi)$ is defined as

$$
\mu(\xi)=\left.\frac{\partial \gamma(\xi, \eta)}{\partial \eta}\right|_{\eta=1}
$$

The non-dimensional mass flux has been calculated for two wall temperatures of $\theta_{w}=-1$ $\left(T_{w}<T_{0}\right)$ and $\theta_{w}=0\left(T_{w}=T_{0}\right)$ and the results are shown in Fig. 6. The local mass flux is significantly high at the inlet region $(\xi \leq 0.05)$ due to a thin concentration boundary layer. The mass flux declines along the flow direction. At high flow length $(\xi \geq 10)$, the local mass flux drops rapidly.

At the entrance region up to a flow length of $\xi \approx 0.05$ the local mass flux is independent of the cooling wall temperature. Beyond this flow length, the two thermal boundary layers formed at the solution interface with the vapor and the cooling wall meet and the effect of cooling wall temperature becomes more evident. The uniform velocity profile assumption results in underestimation of the local mass flux up to a flow length of $\xi \approx 20$ for both cooling wall temperatures. This trend does reverse after $\xi \approx 20$. This difference in the local mass fluxes between the two velocity profiles in the high mass flux region $(\xi \leq 20)$ can result in a significant error in calculating the overall absorption rate. The error can reach up to $30 \%$ for short absorbers or for high solution flow rates.

It should be noted that even though the water concentration is higher in the case of the uniform velocity profile, the local mass flux is higher for the linear velocity profile up to a flow length of $\xi \approx 20$, as shown in Fig. 6. As the schematic of Fig. 7 illustrates, a higher solution velocity at the interface in the case of the linear velocity profile results in a higher convective mass flux (proportional to the product of velocity and concentration) and hence a higher absorption rate. 


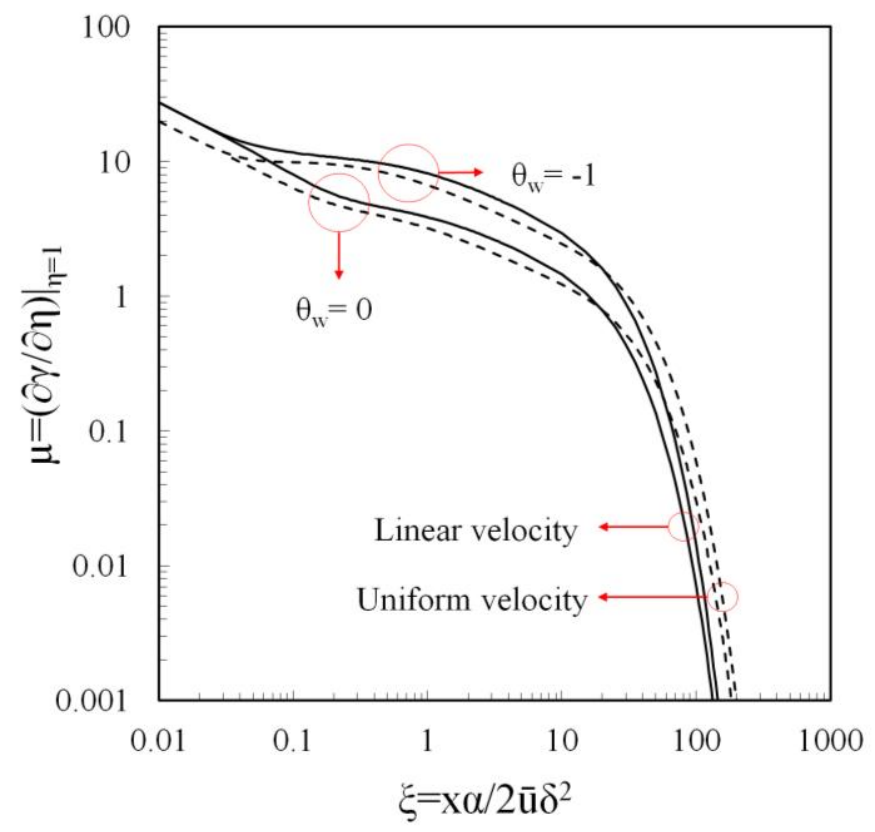

Figure 6. Dimensionless local mass flux at the interface along the flow length; $L e=100$, $S t=0.1$

(a)

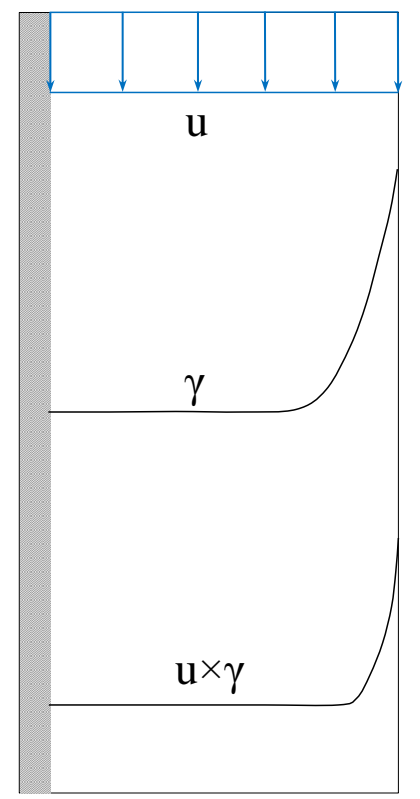

(b)

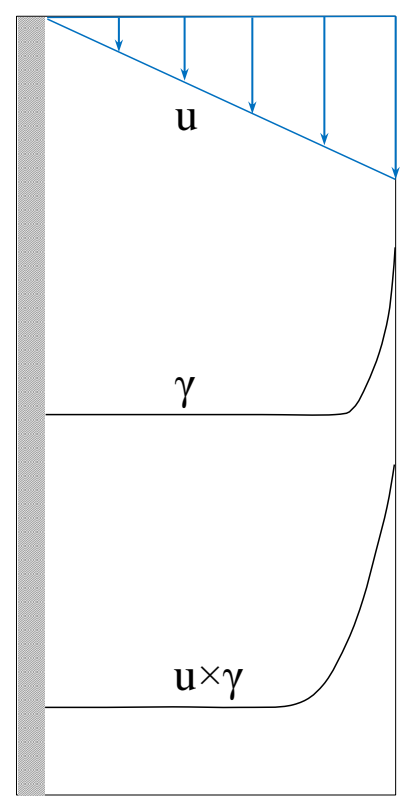

Figure 7. Velocity, refrigerant concentration and the product of velocity and concentration for (a) uniform velocity and (b) linear velocity profiles 
It is also useful to compare the results of this analysis (with a linear velocity profile) with results for the actual velocity profile (i.e. parabolic). Fig. 8 compares the nondimensional mass flux calculated using different velocity profiles. The non-dimensional mass flux values for the parabolic velocity profile are determined from (Grossman, 1983) that involved a numerical solution. As the results suggest, the local mass flux determined using the linear velocity profile assumption more closely follows the one calculated using the parabolic velocity profile than that of a uniform velocity profile.

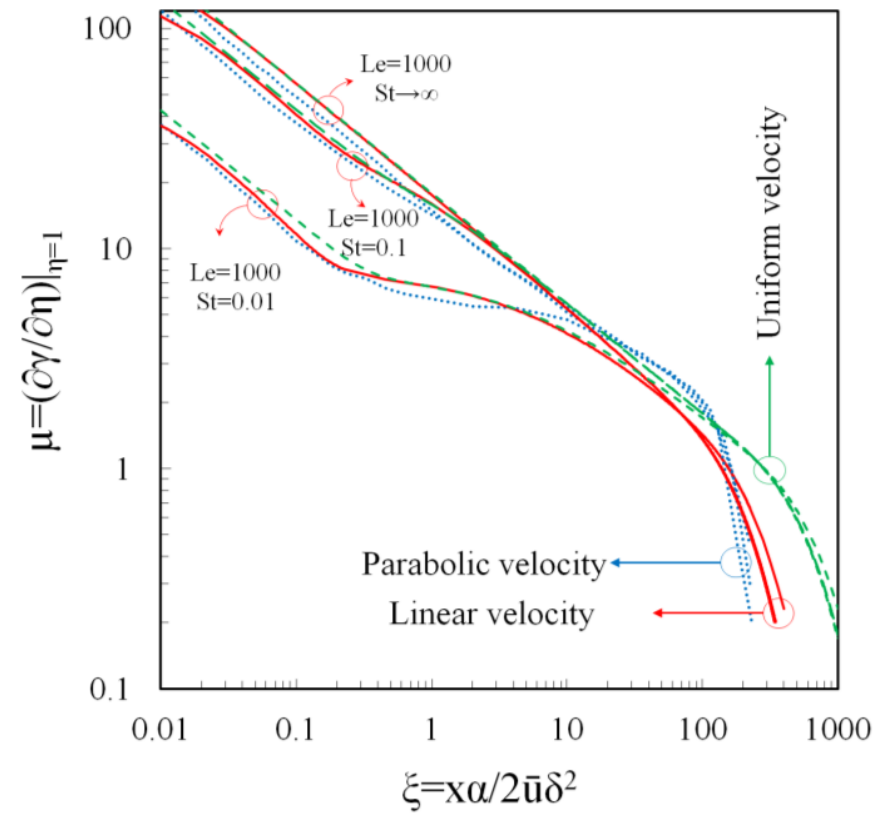

Figure 8. Dimensionless local mass flux at the interface along the flow length for uniform, linear and parabolic velocity profiles.

In the following section, the developed model will be used to investigate the effect of working condition on the absorption rate, and the results will be compared with experimental and numerical results from the literature.

\subsection{Effect of working conditions on the absorption rate}

The driving force for the absorption process is the difference between the refrigerant (water) vapor pressure in the $\mathrm{LiBr}$ solution and the vapor phase. Any change in the temperature and concentration of the solution phase results in changes in the pressure potential and hence the absorption rate. Many parameters such as refrigerant vapor pressure in the absorber, solution flow rate, solution inlet concentration, cooling water 
inlet temperature and solution inlet temperature affect the absorption process. In this section, the effect of the refrigerant vapor pressure and solution flow rate (two of the most important parameters) on the absorption rate is investigated and compared with different absorption data reported in the literature for falling films in various configurations.

The absorption rate for $\mathrm{LiBr}$ solutions falling on a vertical wall are calculated. The thermophysical properties used to calculate the absorption rate are summarized in Table 1. The absorption rate is calculated by averaging the dimensionless local mass flux (c.f. Fig. 6) along the flow length from $\xi=0$ to $\xi_{\text {exit }}$. The $\xi_{\text {exit }}$ is calculated using Eq. 13 for absorbers with different length, and a film thickness and average velocity that are related to the flow rate using Eqs. 51 and 52. The absorption rate is then calculated using the following equation:

$\dot{m}_{a b s}=\rho_{s} D_{s} \frac{\overline{\partial C(x, \delta)}}{\partial y}=\frac{\rho_{s} D_{s}\left(\mathrm{C}_{e}-\mathrm{C}_{0}\right)}{\delta} \frac{\overline{\partial \gamma(x, \delta)}}{\partial \eta}$

where the average values are calculated over the entire flow length.

Table 1. Input parameters for calculating the absorption rate

\begin{tabular}{ll}
\hline Thermophysical property & value \\
\hline Dynamic viscosity $\mu_{s}$ & $0.005 \mathrm{~Pa} \mathrm{~s}$ \\
Diffusion coefficient $D_{s}$ & $5 \times 10^{-10} \mathrm{~m}^{2} \mathrm{~s}^{-1}$ \\
Thermal conductivity $\lambda_{s}$ & $0.42 \mathrm{~W} \mathrm{~m}^{-1} \mathrm{~K}^{-1}$ \\
Specific heat capacity $c_{p}$ & $2 \mathrm{~kJ} \mathrm{~kg}^{-1} \mathrm{~K}^{-1}$ \\
Modified Stefan number $S t$ & $0.1-0.11$ \\
Lewis number $L e$ & 257 \\
\hline
\end{tabular}


The configuration, size and operating conditions of a set of studies considered for the comparison are summarized in Table 2.

Table 2. Operating conditions of various absorber configurations from the literature

\begin{tabular}{|c|c|c|c|c|c|c|c|}
\hline Study & Configuration & $\begin{array}{l}\text { Absorber } \\
\text { length } \\
(\mathrm{cm})\end{array}$ & $\begin{array}{l}\text { Solution flow rate } \\
\quad\left(\mathrm{kg} \mathrm{min}^{-1} \mathrm{~m}^{-1}\right)\end{array}$ & $\begin{array}{c}\text { Water vapor } \\
\text { pressure }(\mathrm{kPa})\end{array}$ & $\begin{array}{c}\text { Solution inlet } \\
\text { temperature } \\
\left({ }^{\circ} \mathrm{C}\right)\end{array}$ & $\begin{array}{c}\text { Cooling wall } \\
\text { temperature } \\
\left({ }^{\circ} \mathrm{C}\right)\end{array}$ & $\begin{array}{c}\text { Inlet } \\
\text { concentration } \\
\text { (wt } \% \mathrm{LiBr} \text { ) }\end{array}$ \\
\hline $\begin{array}{l}\text { Medrano et al., } \\
2002 \text { (in Fig.9) }\end{array}$ & Vertical tube & 120 & 5 & $1-1.5$ & 40 & 30 & 60 \\
\hline $\begin{array}{l}\text { Medrano et al., } \\
2002 \text { (in Fig. } 10 \text { ) }\end{array}$ & Vertical tube & 120 & $5-15$ & 1.3 & 45 & 35 & 60 \\
\hline $\begin{array}{l}\text { *Karami and } \\
\text { Farhanieh, } 2009\end{array}$ & Vertical wall & 120 & $0.35-11$ & 1.3 & 45 & 35 & 60 \\
\hline Sun et al., 2010 & Horizontal tube & 45 & 2.4 & $1-3$ & 45 & 32 & 60 \\
\hline Islam 2008 & Horizontal tube & 71 & 5.1 & $1-3$ & 37 & 32 & 60 \\
\hline
\end{tabular}

* This is a numerical study

The absorption rate versus the vapor pressure determined using the model is presented in Fig. 9 for the test conditions provided in Table 2. Overall, a good agreement is achieved between the model predictions and the experimental data for a vertical tube (Medrano et al., 2002) and two horizontal tube (Islam, 2008; Sun et al., 2010) absorbers. The results suggest that the absorption rate increases almost linearly with the vapor pressure for the presented cases. As the vapor pressure inside the absorber increases, the equilibrium concentration of water at the interface increases leading to a higher mass transfer driving potential and absorption rate. 


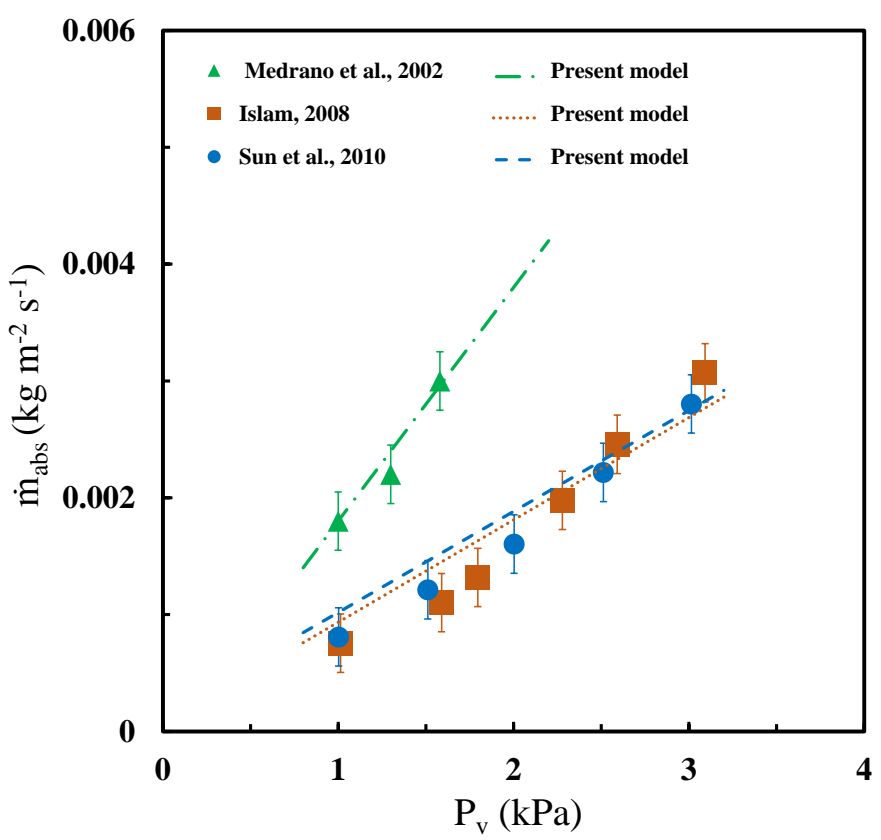

Figure 9. Variation of absorption rate as a function of vapor pressure

The solution flow rate is another important factor that impacts the absorption rate. In Fig. 10, absorption results are compared with those of other absorber designs available in the literature (Karami and Farhanieh, 2009; Medrano et al., 2002). Absorption rates are calculated using the developed model by changing the solution flow rate from $\Gamma=0.55-10$ $\mathrm{kg} \mathrm{min}{ }^{-1} \mathrm{~m}^{-1}$ while keeping the other operating conditions at those provided in Table 2. Since the variation in the flow rate is significant, the abscissa is displayed on a logarithmic scale. The absorption rate increases with the flow rate initially but slows down at high flow rates. A similar trend can be seen for the numerical results of a falling film over a vertical wall (Karami and Farhanieh, 2009). These comparisons suggest that the model prediction is in a good agreement with the experimental and numerical results.

As the solution flow rate increases, the solution film thickness as well as the solution average velocity increases. Since the thermal resistance between the solution-vapor interface, at which the water vapor heat of phase change is released (cf. Fig. 1), and the cooling surface is a function of $\delta / \lambda_{s}$ ( $\delta$ is the solution film thickness and $\lambda_{s}$ is the solution thermal conductivity), increasing the solution film thickness increases the 
thermal resistance and inhibits (Kaynakli, 2008) cooling of the solution-vapor interface resulting in a higher water pressure in the solution phase. A higher water pressure decreases the pressure potential and the absorption rate. On the other hand, as the flow rate increases, the solution inside the absorber is replenished faster with the absorbent rich solution leading to an increase in the driving pressure potential and consequently the absorption rate. These two opposing effects results in a plateau in the absorption rate.

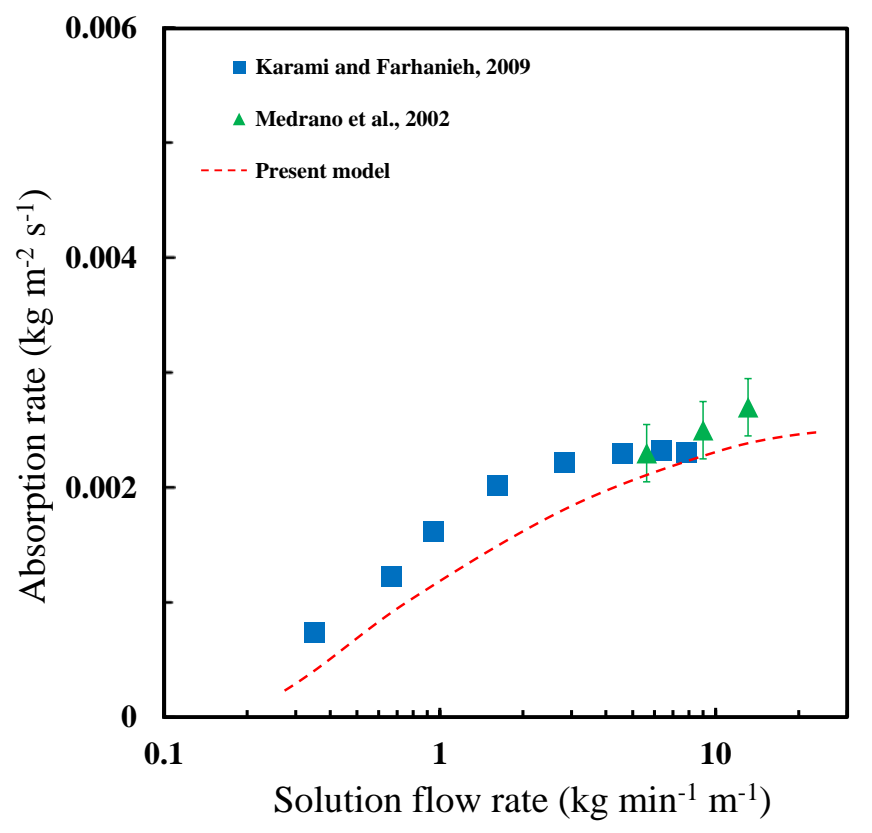

Figure 10. Variation of absorption rate as a function of solution flow rate

\section{Conclusion}

The conjugate heat and mass transfer process taking place during the absorption of a refrigerant vapor into a falling liquid film was analyzed under a linear velocity profile assumption. The Laplace transform method and the residue theorem were utilized in the proposed analysis. This solution method is applicable to the entire flow domain. The concentration and temperature profiles as well as the local mass flux along the flow length at different cooling water temperatures were compared for the uniform and linear velocity assumptions. It was shown that even though the solution water concentration is higher in the case of the uniform velocity profile, the local mass flux is higher for the 
linear velocity profile for most of the flow length due to a higher solution velocity at the solution-vapor interface. It was determined that solutions based on the uniform and linear velocity profiles predict the overall absorption rate by $30 \%$ difference. The new model could accurately predict the experimental and numerical results on the effect of vapor pressure and solution flow rate on the absorption rate.

\section{Acknowledgments}

This study was funded by a Grant from the Advanced Research Projects Agency-Energy (ARPA-E) under contract DE-AR0000133.

\section{APPENDIX A}

In this appendix the proof for Eq. 21 is presented. Referring to Fig. A.1, it can be seen that the points $\left(\mathrm{C}_{0}, \mathrm{~T}_{\mathrm{e}}\right),\left(\mathrm{C}_{\mathrm{i}}, \mathrm{T}_{\mathrm{i}}\right)$ and $\left(\mathrm{C}_{\mathrm{e}}, \mathrm{T}_{0}\right)$ are all located on the linearized saturated curve at a vapor pressure, P. According to Eq. 8 there is a linear relationship between the temperature and concentration at the interface for each vapor pressure, hence:

$T_{e}=k_{1}-k_{2} \cdot C_{0}(\mathrm{~A} .1)$

$T_{i}=k_{1}-k_{2} \cdot C_{i}(\mathrm{~A} .2)$

$T_{0}=k_{1}-k_{2} \cdot C_{e}(\mathrm{~A} .3)$

Substituting these equations into Eq. 21

$\theta(\xi, \eta=1)+\gamma(\xi, \eta=1)=\frac{T_{i}-T_{0}}{T_{e}-T_{0}}+\frac{C_{i}-C_{0}}{C_{e}-C_{0}}=\frac{C_{e}-C_{i}}{C_{e}-C_{0}}+\frac{C_{i}-C_{0}}{C_{e}-C_{0}}=1$ 


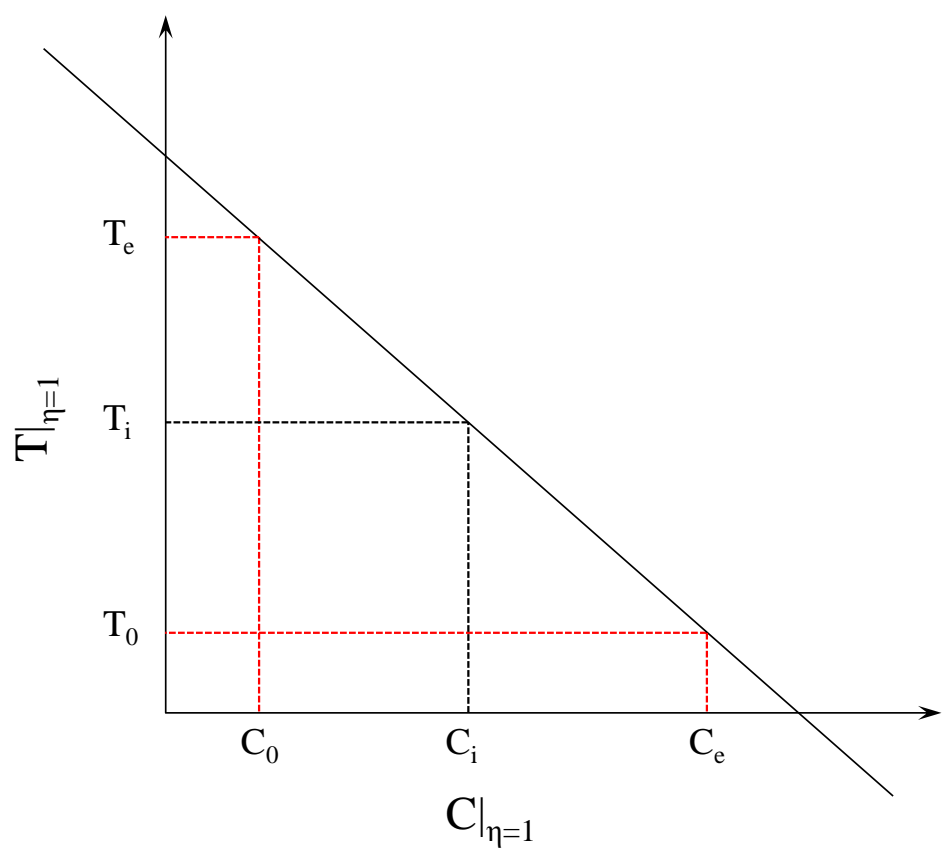

Figure A.1. Linearized saturation curve at the interface

\section{APPENDIX B}

In this appendix the proof for Eq. 44 is presented. Suppose that a function $F(s)$ is analytic throughout the finite plane except for a finite number of isolated singularities $s_{1}, s_{2}, \ldots, S_{n}$. The Bromwich integral gives the inverse Laplace transform of $F(s)$

$f(t)=\mathcal{L}^{-1}\{F(s)\}(t)=\frac{1}{2 \pi i} \lim _{R \rightarrow \infty} \int_{\sigma-i R}^{\sigma+i R} e^{s t} F(s) d s \quad(t>0)$

The integration is done along a vertical line segment $\left(L_{R}\right)$ from $s=\sigma-i R$ to $s=\sigma+i R$ where $\sigma$ is a real positive number and is larger than the real parts of all the singularities of $F(s)$ (Fig. B.1). Residues can be used to evaluate the limit in Eq. B.1. The residue theorem states that if $F(s)$ is analytic inside a closed contour $\mathrm{C}$ (positive counterclockwise) except at points $s_{1}, s_{2}, \ldots, S_{n}$ where $F(s)$ has singularities, then 


$$
\int_{L_{R}} e^{s t} F(s) d s+\int_{C_{R}} e^{s t} F(s) d s=2 \pi i \sum_{n=1}^{N} \operatorname{Re}_{s=s_{n}}\left[e^{s t} F(s)\right] \quad(t>0)
$$

Letting $R$ tend to $\infty$ it can be shown that (Scott et al., 1985)

$$
\lim _{R \rightarrow \infty} \int_{C_{R}} e^{s t} F(\mathrm{~s}) d s=0 \quad(\mathrm{~B} .3)
$$

which shows

$$
f(t)=\sum_{n=1}^{N} \operatorname{Re}_{s=s_{n}}\left[e^{s t} F(s)\right]
$$

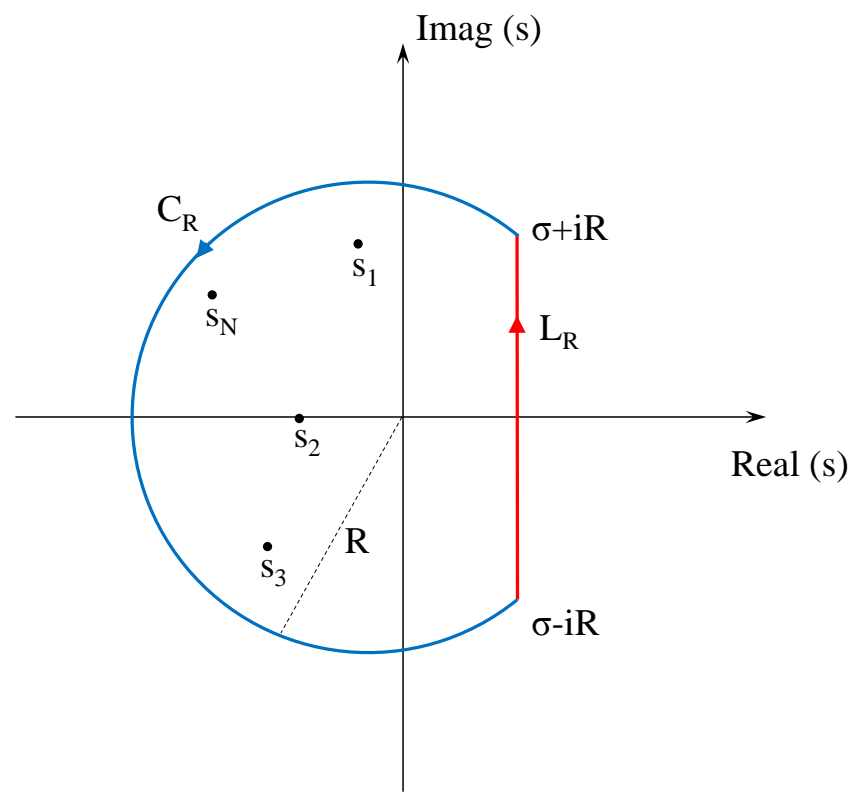

Figure B.1. Integration curves for use in computing the inverse transform

\section{References}

Bigham, S., Nasr Isfahani, R., Moghaddam, S., 2014a. Direct molecular diffusion and micro-mixing for rapid dewatering of $\mathrm{LiBr}$ solution. Appl. Therm. Eng. 64, 371375. doi:10.1016/j.applthermaleng.2013.12.031

Bigham, S., Yu, D., Chugh, D., Moghaddam, S., 2014b. Moving beyond the limits of mass transport in liquid absorbent microfilms through the implementation of surface-induced vortices. Energy 65, 621-630. doi:10.1016/j.energy.2013.11.068 
Cerezo, J., Bourouis, M., Vallès, M., Coronas, A., Best, R., 2009. Experimental study of an ammonia-water bubble absorber using a plate heat exchanger for absorption refrigeration machines. Appl. Therm. Eng. 29, 1005-1011.

doi:10.1016/j.applthermaleng.2008.05.012

Dong, L., Zheng, D., Nie, N., Li, Y., 2012. Performance prediction of absorption refrigeration cycle based on the measurements of vapor pressure and heat capacity of H2O+[DMIM]DMP system. Appl. Energy 98, 326-332. doi:10.1016/j.apenergy.2012.03.044

Grigoryeva, N.I., Nakoryakov, V.E., 1977. Exact solution of combined heat- and masstransfer problem during film absorption. J. Eng. Phys. 33, 1349-1353.

Grossman, G., 1983. Simultaneous heat and mass transfer in film absorption under laminar flow. Int. J. Heat Mass Transf. 26, 357-371. doi:10.1016/00179310(83)90040-6

Islam, M.R., 2008. Absorption process of a falling film on a tubular absorber: An experimental and numerical study. Appl. Therm. Eng. 28, 1386-1394. doi:10.1016/j.applthermaleng.2007.10.004

Jeong, S., Garimella, S., 2002. Falling-film and droplet mode heat and mass transfer in a horizontal tube LiBr/water absorber. Int. J. Heat Mass Transf. 45, 1445-1458. doi:10.1016/S0017-9310(01)00262-9

Karami, S., Farhanieh, B., 2009. A numerical study on the absorption of water vapor into a film of aqueous LiBr falling along a vertical plate. Heat Mass Transf. 46, 197-207. doi:10.1007/s00231-009-0557-y

Kaynakli, O., 2008. The first and second law analysis of a lithium bromide/water coil absorber. Energy 33, 804-816. doi:10.1016/j.energy.2008.01.009

Kim, D.S., Infante Ferreira, C.A., 2008. Solar refrigeration options - a state-of-the-art review. Int. J. Refrig. 31, 3-15. doi:10.1016/j.ijrefrig.2007.07.011

Kurnia, K.A., Pinho, S.P., Coutinho, J.A.P., 2014. Designing ionic liquids for absorptive cooling. Green Chem. 16, 3741. doi:10.1039/C4GC00954A

Medrano, M., Bourouis, M., Coronas, A., 2002. Absorption of water vapour in the falling film of water-lithium bromide inside a vertical tube at air-cooling thermal conditions. Int. J. Therm. Sci. 41, 891-898. doi:10.1016/S1290-0729(02)01383-2

Meyer, T., 2014. Analytical solution for combined heat and mass transfer in laminar falling film absorption with uniform film velocity - Isothermal and adiabatic wall. Int. J. Refrig. 48, 74-86. doi:10.1016/j.ijrefrig.2014.08.005

Mortazavi, M., Nasr Isfahani, R., Bigham, S., Moghaddam, S., 2015. Absorption characteristics of falling film $\mathrm{LiBr}$ (lithium bromide) solution over a finned structure. Energy. doi:10.1016/j.energy.2015.04.074

Nakoryakov, V.E., Grigor'eva, N.I., 1977. Combined heat and mass transfer during absorption in drops and films. J. Eng. Phys. 32, 243-247. doi:10.1007/BF00865776

Nakoryakov, V.E., Grigor'eva, N.I., Potaturkina, L. V., 1997. Analysis of Exact Solutions to Heat- and MAass-Transfer Problems for Absorption with Films or Streams. Theor. Found. Chem. Eng. 31, 119-126.

Nakoryakov, V.E., Grigoryeva, N.I., 2010. Nonisothermal absorption in thermotransformers. J. Eng. Thermophys. 19, 196-271. doi:10.1134/S1810232810040028 
Nakoryakov, V.E., Grigoryeva, N.I., Bartashevich, M. V., 2011. Heat and mass transfer in the entrance region of the falling film: Absorption, desorption, condensation and evaporation. Int. J. Heat Mass Transf. 54, 4485-4490. doi:10.1016/j.ijheatmasstransfer.2011.06.032

Nasr Isfahani, R., Fazeli, A., Bigham, S., Moghaddam, S., 2014. Physics of lithium bromide ( $\mathrm{LiBr}$ ) solution dewatering through vapor venting membranes. Int. J. Multiph. Flow 58, 27-38. doi:10.1016/j.ijmultiphaseflow.2013.08.005

Nasr Isfahani, R., Moghaddam, S., 2013. Absorption characteristics of lithium bromide $(\mathrm{LiBr})$ solution constrained by superhydrophobic nanofibrous structures. Int. J. Heat Mass Transf. 63, 82-90. doi:10.1016/j.ijheatmasstransfer.2013.03.053

Nasr Isfahani, R., Sampath, K., Moghaddam, S., 2013. Nanofibrous membrane-based absorption refrigeration system. Int. J. Refrig. 36, 2297-2307. doi:10.1016/j.ijrefrig.2013.07.019

Palacios, E., Izquierdo, M., Marcos, J.D., Lizarte, R., 2009. Evaluation of mass absorption in LiBr flat-fan sheets. Appl. Energy 86, 2574-2582. doi:10.1016/j.apenergy.2009.04.033

Saha, B.., Akisawa, A., Kashiwagi, T., 2001. Solar/waste heat driven two-stage adsorption chiller: the prototype. Renew. Energy 23, 93-101. doi:10.1016/S09601481(00)00107-5

Scott, D.B., Churchill, R. V., Brown, J.W., 1985. Complex Variables and Applications. Math. Gaz. 69, 243. doi:10.2307/3617559

Sun, J., Fu, L., Zhang, S., Hou, W., 2010. A mathematical model with experiments of single effect absorption heat pump using LiBr-H2O. Appl. Therm. Eng. 30, 27532762. doi:10.1016/j.applthermaleng.2010.07.032

Warnakulasuriya, F.S.K., Worek, W.M., 2008. Drop formation of swirl-jet nozzles with high viscous solution in vacuum-new absorbent in spray absorption refrigeration. Int. J. Heat Mass Transf. 51, 3362-3368. doi:10.1016/j.ijheatmasstransfer.2007.11.015

Yu, D., Chung, J., Moghaddam, S., 2012. Parametric study of water vapor absorption into a constrained thin film of lithium bromide solution. Int. J. Heat Mass Transf. 55, 5687-5695. doi:10.1016/j.ijheatmasstransfer.2012.05.064

Zheng, D., Dong, L., Huang, W., Wu, X., Nie, N., 2014. A review of imidazolium ionic liquids research and development towards working pair of absorption cycle. Renew. Sustain. Energy Rev. 37, 47-68. doi:10.1016/j.rser.2014.04.046 